\title{
PRODUCTION OF COAL BASED ACTIVATED CARBON BY MICROWAVE - INDUCED CHEMICAL ACTIVATION
}

\author{
Echegi Christian Uche \\ Department of Chemical Engineering, Institute of Management and Technology, Enugu, \\ Nigeria. \\ E-mail: uscechegi@yahoo.com
}

\section{ABSTRACT}

Coal-based activated carbons are produced from Enugu coal by Microwave - induced chemical activation. The precursor was subjected to carbonization at temperature of $800^{\circ} \mathrm{C}$ for 2 hours and activated in 2540MHZ Microwave oven using $\mathrm{KOH}$ - activating agent. The effect of the process variables on the characterized properties of the activated carbon such as surface area, iodine number, pore volume, porosity etc are investigated. The result showed that the adsorption capacity of activated carbon produced increases with process variables until maximum value is attained and thereafter a gradual decrease set in. The best activated carbons are obtained using microwave power of $729 \mathrm{~W}$, radiation time of 8 minutes and impregnation ratio of $1 / 2$. The high quality of these properties recorded indicates that microwave - induced chemical activation is one of the best alternatives for the production of activated carbon from coal.

\subsection{Introduction}

Activated carbon (AC) is a carbonaceous substance derived from special treatment of solid state carbon material. The production procedure is designed toward achieving microcrystalline structure characterized by large surface, high pore volume distribution, controllable pore structure, thermo-stability, low acid/base reactivity and rapid adsorption capacity ( $\mathrm{Li}$ et al, 2009). AC applications range from the waste water treatment of volatile organic compound (VOC), purification of industrial effluents, refining of vegetable oils, decolourization of petroleum products, energy storage as well as in pharmaceutical industries for drug production. Recently, research interest has shifted toward its use in direct contact with blood as an artificial kidney, remediation of the contaminated soil and as catalyst and catalytic support in process industries for catalytic reaction optimization (Echegi, 2017).

AC can be produced from fossil fuel based materials such as coal, peat, lignin and other carbonaceous materials like wool, sawdust, rice husks, corn cobs, coconut shells etc. Due to differences in composition and organic matter content which modify porosities, textural and surface properties of the desirable (activated) carbon, coal has been found to be the most favoured precursor (Rafsanjani et al 2013), while alkali-based activating agents enjoy dominant superiority in high quality production of AC from carbonaceous materials [Echegi, 2017; Rafsanjani et al, 2013].

The activation process plays a significant role in the pore structure development and distribution, vis-a-vis adsorption capacity of the prepared AC. There are two types of activation, namely, physical and chemical activation. In physical activation, the suitable carbon precursors are prolysed under an inert atmosphere at a moderate temperature, about $600-800^{\circ} \mathrm{c}$ to release volatile matters and produce chars with rudimentary pore structures. 
Due to the blockage of pores by tars, the internal surface area and other adsorption potentials are too low and in most cases below the standard specifications in adsorbent ranking (Echegi, 2019). Subsequently, the chars are subjected to partial gasification at higher temperature (usually above $800^{\circ} \mathrm{c}$ ) with oxidizing air, steam, carbon dioxide or their mixtures, to produce AC with higher developed and accessible internal porosities (Cuhadaroglu et al, 2008). Whereas in chemical activation, both carbonization and activation stages are conducted simultaneously at the same temperature. In this case the precursor is impregnated with an activating agent and the impregnated material is heat-treated at moderate temperature in an inert atmosphere such as tubular furnace.

However, in some cases, this conventional method of heating may take several hours, even up to week to reach the desired level of activation leading to extra processing cost due to higher amount of energy consumption for the extended period. Another problem lies in the furnace where surface heating from the hearth wall does not ensure a uniform temperature for different shapes and sizes of sample. This generates thermal gradient from the hot surface of the sample particle to its interior and impedes the effective removal of gaseous products to its surroundings, thereby resulting in a detrimental effect on the quality of the AC obtained (Foo and Hameed, 2009). Secondly, there is a considerable risk of overheating or even thermal run away of local sample, leading to a complete combustion of the carbon (Hesas et al, 2013; Adekunle and Farid, 2017).

For several decades, the conventional heating method remains the most preferable and applicable technique in the production of AC. However, the advent of microwave method of heating provided the needed solution to all these setbacks associated with the conventional heating method of production of AC from carbonaceous material [Adenkule et al, 2017]. In this technique, as corroborated by Foo and Hameed (2012), heat is transferred to the sample via electromagnetic wave with a high conversion efficiency of $50 \%$ for $2450 \mathrm{MH}_{\mathrm{Z}}$ and $85 \%$ for $915 \mathrm{MHz}$. The transferred energy is converted into heat energy within the char-dielectric material by dipole rotation and ionic conduction.

The heating process is both internal and volumetric, where the huge thermal gradient from the interior of the char sample to the cool surface allows the microwave induced reaction to proceed more quickly and effectively at a lower bulk temperature, providing shorter processing time and saving energy (Hesas et al, 2013). Other advantages of microwave heating are compactness of equipment (small equipment size), pollution free environment, improved safety, simplicity of operation and less automation. Although, obtaining the accurate value of the sample temperature poses a great challenge, the surface temperature of the sample can be measured using an infrared pyrometer.

The recognition of these numerous advantages of microwave heating method informed its consideration and subsequent application in this work. The objective of study is to produce high quality $\mathrm{AC}$ from Enugu sub-bituminous coal by microwave - induced $\mathrm{KOH}$ Chemical activation.

\subsection{Materials and Method}

\subsection{Production of the Coal Sample}

The sourced coal from Enugu coal mine was subjected to preliminary treatment of cleaning, drying, size reduction and sieving. The coal sample was washed with water to remove dirt particles from the surfaces and sun-dried for 2 days at the interval of 8 hours each. The dried sample was crushed and sieved to the mesh size of 1-2mm. 


\subsection{Carbonization}

$50 \mathrm{~g}$ of the ground coal sample was placed into the electric furnace and heated at the rate of $10^{\circ} \mathrm{C}$ per minute from room temperature to $800^{\circ} \mathrm{C}$. After attaining the above temperature, the heating was maintained for 2 hours. Later, the carbonized sample was allowed to cool gradually to ambient temperature.

\subsection{Activation}

The carbonized sample was ground and sieved to a uniform particle range of 0.75 to $1.00 \mathrm{~mm}$. The char product was impregnated with activating agent of $\mathrm{KOH}$ at $\mathrm{KOH} / \mathrm{Char}$ ratios of 1/4, $1 / 3,1 / 2,1 / 1$ and 2/1. The resulting samples were designated M1, M2, M3, M4, and M5 respectively. The mixture was stirred for 2 hours and later filtered, dried over-night at $110^{\circ} \mathrm{C}$ and stored in desiccators.

For the microwave activation, $20 \mathrm{~g}$ of $\mathrm{KOH}$ - impregnated char of sample 1 was added to a ceramic crucible in a cylindrical quartz reactor, placed in a $2450 \mathrm{MHz}$ microwave with a nominal power output of $729 \mathrm{~W}$. The radiation process was conducted for 8 minutes under a $0.5 \mathrm{~L} / \mathrm{min}$ flow of humidified $\mathrm{N}_{2}$. After the microwave activation, the $\mathrm{KOH}$ activated carbon was cooled to room temperature using a flow of humid $\mathrm{N}_{2}$ at the rate of $0.5 \mathrm{~L} / \mathrm{min}$. The activated carbon sample was then mixed with $0.1 \mathrm{~N} \mathrm{HCl}$ and stirred for 1 hour. Later, it was washed with de-ionized water until a $\mathrm{pH}$ range of $6.5-7.5$ was reached. Finally, the AC sample was dried at $100^{\circ} \pm 5^{\circ} \mathrm{C}$ for 24 hours. The same procedure was repeated with the other samples of M2, M3, M4 and M5 of KOH -impregnated char. In the same vein, the effect of microwave power output was studied by conducting the same experiment at different nominal power output of $162 \mathrm{~W}, 324 \mathrm{~W}, 520 \mathrm{~W}$, \& $729 \mathrm{~W}$ and $900 \mathrm{~W}$ at constant impregnation ratio of $1 / 2$ and radiation time of 8 mins. Also at the constant microwave power of $729 \mathrm{~W}$ and impregnation ratio of $1 / 2$, the effect of radiation time was investigated at the exposure time of 4, 6, 8, 10 and 12 minutes. Furthermore, a control experiment was conducted using the same procedure at process conditions of power output of $729 \mathrm{~W}$, radiation time of 8 minutes and impregnation ratio of $1 / 2$ but with the omission of the carbonization of the raw coal. Finally, the characterized properties of surface area, iodine number, pore volume, moisture content, porosity, fixed carbon content, etc of the AC were conducted and evaluated.

\subsection{Result and Discussion}

3.1 Effect of Non-Carbonization of Raw Coal on the Quality of AC

\begin{tabular}{|c|c|c|c|c|c|c|c|c|c|c|}
\hline 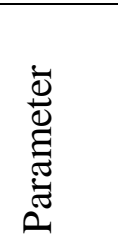 & 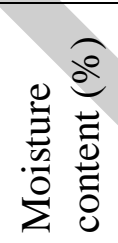 & 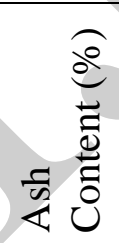 & 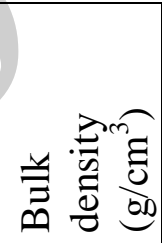 & $\frac{T}{2}$ & 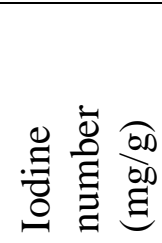 & 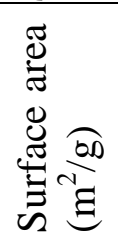 & 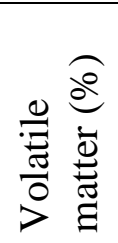 & 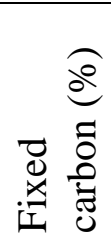 & 冚 & 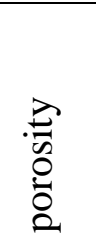 \\
\hline Value & 2.86 & 14.04 & 0.54 & 7.1 & 429 & 501 & 24.63 & 58.47 & 0.39 & 0.52 \\
\hline
\end{tabular}

\subsection{Effect of Power Output on the Quality of AC}

\begin{tabular}{|l|c|c|c|c|c|}
\hline Power output & $\begin{array}{c}162 \mathrm{~W} \\
(18 \%)\end{array}$ & $\begin{array}{c}324 \mathrm{~W} \\
(36 \%)\end{array}$ & $\begin{array}{c}520 \mathrm{~W} \\
(58 \%)\end{array}$ & $\begin{array}{c}729 \mathrm{~W} \\
(81 \%)\end{array}$ & $\begin{array}{c}900 \mathrm{~W} \\
(100 \%)\end{array}$ \\
\hline Moisture Content (\%) & 2.91 & 2.43 & 2.28 & 2.16 & 1.85 \\
\hline Ash Content $(\%)$ & 10.87 & 10.99 & 11.07 & 11.26 & 13.32 \\
\hline Bulk density $\left(\mathrm{g} / \mathrm{cm}^{3}\right)$ & 0.55 & 0.55 & 0.54 & 0.53 & 0.54 \\
\hline $\mathrm{pH}$ & 6.9 & 6.9 & 6.9 & 7.1 & 6.8 \\
\hline Iodine Number $(\mathrm{mg} / \mathrm{g})$ & 299 & 792 & 984 & 1225 & 972 \\
\hline
\end{tabular}




\begin{tabular}{|l|c|c|c|c|c|}
\hline \hline Surface Area $\left(\mathrm{m}^{2} / \mathrm{g}\right)$ & 360 & 896 & 1074 & 1380 & 1026 \\
\hline Pore Volume $\left(\mathrm{cm}^{3} / \mathrm{g}\right)$ & 0.38 & 0.42 & 0.47 & 0.51 & 0.45 \\
\hline Porosity & 0.41 & 0.48 & 0.58 & 0.64 & 0.60 \\
\hline Volatile Matter $(\%)$ & 30.12 & 27.26 & 20.83 & 12.57 & 12.44 \\
\hline Fixed Carbon $(\%)$ & 56.20 & 60.84 & 65.82 & 74.01 & 72.39 \\
\hline
\end{tabular}

\subsection{Effect of Impregnation Ratio on the Quality of AC}

\begin{tabular}{|l|c|c|c|c|c|}
\hline \multicolumn{1}{|c|}{ Impregnation Ratio } & & & & \\
\hline Moisture Content $(\%)$ & $1 / 4$ & $1 / 3$ & $1 / 2$ & $1 / 1$ & $2 / 1$ \\
\hline Ash Content $(\%)$ & 2.85 & 2.46 & 2.28 & 2.09 & 1.89 \\
\hline Bulk density $\left(\mathrm{g} / \mathrm{cm}^{3}\right)$ & 10.76 & 12.06 & 12.01 & 12.85 & 12.77 \\
\hline $\mathrm{pH}$ & 0.54 & 0.55 & 0.52 & 0.50 & 0.50 \\
\hline Iodine Number $(\mathrm{mg} / \mathrm{g})$ & 7.0 & 7.0 & 7.2 & 7.1 & 7.2 \\
\hline Surface Area $\left(\mathrm{m}^{2} / \mathrm{g}\right)$ & 497 & 909 & 1258 & 986 & 809 \\
\hline Pore Volume $\left(\mathrm{cm}^{3} / \mathrm{g}\right)$ & 680 & 1008 & 1436 & 1007 & 964 \\
\hline Porosity & 0.38 & 0.52 & 0.61 & 0.54 & 0.50 \\
\hline Volatile Matter $(\%)$ & 0.45 & 0.56 & 0.68 & 0.61 & 0.58 \\
\hline Fixed Carbon $(\%)$ & 31.25 & 24.61 & 10.25 & 11.97 & 10.20 \\
\hline
\end{tabular}

\subsection{Effect of Radiation Time on the Quality of AC}

\begin{tabular}{|l|c|c|c|c|c|}
\hline Radiation Time & & & & \\
\hline Moisture Content $(\%)$ & 4 mins & 6 mins & 8 mins & 10 mins & 12 mins \\
\hline Ash Content $(\%)$ & 2.67 & 2.48 & 2.14 & 2.01 & 2.01 \\
\hline Bulk density $\left(\mathrm{g} / \mathrm{cm}^{3}\right)$ & 12.86 & 14.01 & 14.41 & 15.24 & 15.44 \\
\hline $\mathrm{pH}$ & 0.57 & 0.55 & 0.53 & 0.54 & 0.54 \\
\hline Iodine Number $(\mathrm{mg} / \mathrm{g})$ & 6.8 & 7.0 & 7.0 & 6.9 & 7.0 \\
\hline Surface Area $\left(\mathrm{m}^{2} / \mathrm{g}\right)$ & 618 & 891 & 1132 & 1016 & 987 \\
\hline Pore Volume $\left(\mathrm{cm}^{3} / \mathrm{g}\right)$ & 699 & 1082 & 1405 & 1178 & 1064 \\
\hline Porosity & 0.36 & 0.54 & 0.62 & 0.60 & 0.55 \\
\hline Volatile Matter $(\%)$ & 0.48 & 0.56 & 0.69 & 0.64 & 0.63 \\
\hline Fixed Carbon $(\%)$ & 27.82 & 20.59 & 15.26 & 13.92 & 14.01 \\
\hline
\end{tabular}

The result of the microwave-induced chemical activation of coal using $\mathrm{KOH}$ at various process conditions are presented in Tables $3.1-3.4$. The analysis reveals that after the carbonization and activation, the adsorption characteristics of AC such as surface area, pore volume, iodine number, porosity, moisture content, fixed carbon, etc improved tremendously. The observation shows that the values of these assessed properties recorded are dictated by each of the process variables of power output level, radiation time and impregnation ratio of $\mathrm{KOH} / \mathrm{Char}$ employed in the experiment. In addition to the process parameters, the nature of activation is also one of the key factors in the determination of the quality of the AC. For instance, in Table 3.1, the values of these characterized properties of AC obtained were relatively low mainly due to the omission of carbonization process prior to activation in microwave oven. This report is corroborated by Adekunle et al, (2017) on the analysis of the properties of AC produced from biomass using microwave heating. Therefore, with a view to enhancing the quality of the $\mathrm{AC}$, the pretreated coal sample was subjected to complete 
carbonization at elevated temperature of $800^{\circ} \mathrm{C}$ for 2 hours. At the first instance, preliminary experiments on the effects of power output, heating time and impregnation ratio, were conducted to investigate the range of applicability of the process variables vis-a-viz the quality of the AC produced. This indeed, provided proper direction to the approach of some experimental intrigues encountered and led to the simplification of the work.

\section{3(i) Effect of Power Output level on the Properties of AC}

Based on preliminary studies conducted earlier on, the other identifiable two parameters of radiation time and impregnation ratio were maintained constant at 8 minutes and 1/2 respectively during the investigation of the effect of power output level on AC. The increase in microwave nominal power output from $162 \mathrm{~W}$ to $729 \mathrm{~W}$ resulted in substantial improvement of the adsorption capacity of the prepared AC. For instance, the surface area recorded at $162 \mathrm{~W}$ is a mere value of $360 \mathrm{~m}^{2} / \mathrm{g}$ which is remarkably low in adsorbent rating. The value increased with the power output and reached a maximum value of $1380 \mathrm{~m}^{2} / \mathrm{g}$ at $729 \mathrm{~W}$. However, further increase in power level to $900 \mathrm{~W}$, the surface area obtained, declined to $1026 \mathrm{~m}^{2} / \mathrm{g}$. Similarly, the iodine number increased from 299 to $1225 \mathrm{mg} / \mathrm{g}$ and thereafter took a down turn and decreased to $972 \mathrm{mg} / \mathrm{g}$ at the above mentioned power output range respectively. Accordingly, the investigation of the effect on the pore structure development in terms of pore volume and porosity of the AC exhibited the same phenomenon of occurrence. Like the surface area and iodine number, the pore structure development and ultimately the adsorption capacity of AC as depicted in Table 3.2 increases with microwave power output up to and optimum mark at the neighbourhood of $729 \mathrm{~W}$. Beyond the optimum power output, all the assessed properties of AC were observed to decline with the increase in nominal microwave power output level. These findings are in consonance with the reports of Hesas et al, (2013) and Foo et al, (2012) on the analysis of quality of AC produced from microwaveinduced chemical activation of agricultural wastes and biodiesel.

At the high power output level, the reaction between the char and activating agent intensifies due to increase in temperature. This leads to higher rate of volatilization of the melted ash and tar, and subsequent creation of large amounts of micropores and mesopores [Amir, 2012; Echegi et al, 2018]. The decrease in these adsorption potentials beyond the optimum power output of the microwave activation may be due to the burning of the carbon and destruction of the pore structures by higher level of radiation. The significant melting of the ash that plausibly blocked the pores in char when cooled to ambient temperature as reported by Zawawi et al, (2017) and corroborated by Amir (2012) arose from the structural deformation and collapse of pore walls at excessive temperature of activation.

\section{3(ii) Effect of Impregnation Ratio on the Quality of AC}

From Table 3.3, it was observed that the adsorption capacity of the prepared AC was appreciably affected by the changes in the concentration of $\mathrm{KOH}$-activating agent. The effects were investigated at various impregnation ratios of $\mathrm{KOH} / \mathrm{Char}$ at $1 / 4,1 / 3,1 / 2,1 / 1$ and $2 / 1$ under the experimental conditions of constant power output level of $729 \mathrm{~W}$ and radiation time of 8 mins. With the increasing ratio from $1 / 4$ to $1 / 2$, all the adsorption properties of $A C$ increased progressively. For instance, the iodine number recorded a significant increment of $761 \mathrm{mg} / \mathrm{g}$ from $497 \mathrm{mg} / \mathrm{g}$ at the range of the ratio of $1 / 4$ to $1 / 2$. This prove of positive effect could not be extended beyond $1 / 2$ as the increase to $1 / 1$ resulted in reduction to $986 \mathrm{mg} / \mathrm{g}$. In the same fashion, the surface area increased to a maximum of $1436 \mathrm{~m}^{2} / \mathrm{g}$ from $680 \mathrm{~m}^{2} / \mathrm{g}$ at the ratio of $1 / 4$ to $1 / 2$. Subsequently, it decreased to $964 \mathrm{~m}^{2} / \mathrm{g}$ as the ratio increased to $2 / 1$. The effect on pore volume development and porosity is also remarkable and thus a confirmation of the factor that concentration of activating agent is one of the key determinants in the 
production of high quality AC from microwave activation. Notably, the concentration of $\mathrm{KOH}$-activating agent produced significant variations on most of the characterized parameters monitored. Generally, the results of these adsorption properties investigated exhibited the same trend of steadily rise to optimum and thereafter a decrease to a minimum as the concentration of $\mathrm{KOH}$ increases. This pattern of occurrence is in agreement with the work of Bouchelta et al (2012) on the study of effect of $\mathrm{NaOH}$-activating agent on AC produced from Petro-chemical Industrial Waste under microwave-induced chemical activation. Similarly, Deng et al (2010) and Liu et al (2010), in their separate works, obtained the same results on the investigation of the effects of microwave power output on the pore structure of AC produced from cotton stalk and bamboo by microwave induced chemical activation.

The role of impregnation agent is to minimize the formation of tars and other liquids that could possibly clog up the pores and inhibit the development of porous structures of AC (Bouchelta et al, 2012). At high concentration of impregnation ratio, it may be inferred that the reaction is highly strengthened. The developed of porosity in $\mathrm{KOH}$ activation may be attributed to the reduction of $\mathrm{KOH}$ to potassium by this spontaneous reaction [Lillo-Rodena et al, 2004; Mao et al, 2015].

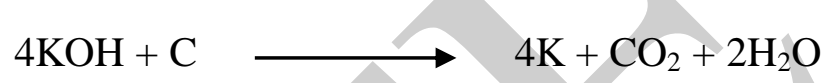

Therefore, by increasing the $\mathrm{KOH} / \mathrm{Char}$ ratio, the activation process is intensified. The potassium species formed during the activation stage diffuse into the internal structure of the char matrix leading to the creation of new pores and widening of the existing ones (Mao et al, 2017; Ejikeme et al, 2015).

\section{3(iii) Effect of Microwave Radiation Time on the Quality of AC}

Based on the findings of the control experiment, the effect of heating time was conducted at the constant microwave power output of $729 \mathrm{~W}$ and impregnation ratio of $1 / 2$ while varying the radiation time from 4 to 12 minutes. From the results in Table 3.4, the characterized adsorption parameters of surface area, pore volume, iodine number, porosity, etc are increased as the radiation time is increased from 4 to 8 minutes. But when the radiation time is increased from 8 to 12 minutes, a drop in adsorption capacity was noticed. At this range, the values of these assessed parameters decreased progressively to minimum. Thus, the finding indicates the attainment of optimum adsorption capacity at the neighbourhood of 8 minutes. Remarkably, the analysis of the result shows that these adsorption parameters do not vary monotonically with the heating time. For instance, the variation of microwave heating time from 4 to 6 minutes resulted in a substantive increment of about $44 \%$ in iodine number. But increasing the heating time from 6 to 8 minutes increased the iodine number by $27 \%$. Similarly, for the surface area, the increments recorded at the above mentioned ranges are $57 \%$ and $30 \%$ respectively. While at the reverse side of the optimum attainment, the iodine number decreased by $11 \%$ from 8 to 10 minutes, whereas the surface area also produced a decrease of $16 \%$. The same trend was observed in other adsorption parameters investigated in this work such as pore volume, porosity, moisture content, fixed carbon etc.

The findings obtained in this work correlated with the earlier studies by Deng et al (2010), Foo and Hameed (2012) and Li et al (2009) in their respective research works on the effect of heating time on the adsorption capacity of AC prepared by the method of microwave-induced chemical activation. Also Hesas et al (2013), observed that the adsorption capacity of AC decreases when the activation time increases beyond the optimum value in the activation 
stage. The same adsorption trend was reported by Mao et al (2017) for the AC's produced at different radiation times in microwave-assisted $\mathrm{KOH}$ activation of Pinewood and Wheat straw. These findings indicate that prolonging exposure to microwave radiation results in an increase in temperature which in turn increases the reaction rate, thus improving those aforementioned adsorption parameters. It may be attributed that the drop in adsorption capacity of AC after the optimum time is due to drastic rise in temperature and localization of hot spot in the char and the subsequent ablation as well as shrinkage of the AC channels and skeleton.

\subsection{Conclusion}

In this study, microwave-induced high quality $\mathrm{AC}$ was produced from Enugu sub-bituminous coal. In the formatted procedure of production, carbonization of the precursor is found to be indispensable. The characterized properties of the $\mathrm{AC}$ obtained are functions of process variables of normal power input, radiation time and impregnation ratio of $\mathrm{KOH}$ to char. Each of the process variables increased with the adsorption characteristic until a maximum value is attained after which further increase leads to a gradual reduction. The general analysis of the report reveals that the microwave-induced chemical activation is a potential alternative and simpler method of producing high quality AC from coal.

\section{Acknowledgement}

The author acknowledged the Tertiary Education Trust Fund (TETFUND) Nigeria for the research grant provided that made this work possible.

\section{REFERENCES}

1. Adekule Moshood Abioye and Farid Nasir Ani (2017), Advancement in the Production of Activated Carbon from Biomass using Microwave Heating, Research Gate Jurnal Teknologi, 79:3, 79-88.

2. Amir Shabanzadeh (2012), Production of Activated Carbon within the Indirect Gasification Process. Master Degree Thesis, Chalmers University of Technology, Gothenburg, Sweden, 6-12.

3. Bouchelta Chafia, Chekkat Fatiha Ahmed, Marsa Zoubida, Ramdane Narsima and Mediram Mohammed Salah (2012), Preparation of Activated Carbon from Petrochemical Industrial Waste by $\mathrm{NaOH}$ activation under Microwave Radiation, Application in Dyes Adsorption, Jordan Journal of Chemistry, Vol. 7, No. 3, 253-266.

4. Cuhadaroglu Dilek and Uygun Oznur A. (2008), Production and Characterization of Activated Carbon from a Bituminous Coal by Chemical Activation, African Journal of Biotechnology Vol.7 (20); $3703-3710$.

5. Deng H. Li G., Yang H., Tang J. and Tang J. (2010), Preparation of Activated Carbons from Cotton Stalk by Microwave Assisted $\mathrm{KOH}$ and $\mathrm{K}_{2} \mathrm{CO}_{3}$ Activation, Chemical engineering Journal, 163(3): 373-381.

6. Echegi U.S.C (2017), Activated Carbon: Production, Properties and Application: A Review, International Journal of the Arts and the Sciences Vol.3, No.1, $61-68$. 
7. Echegi U.S.C and Eze K.A (2018) The Quality of Activated Carbon produced from Coal by Chemical Activation, Chemistry Research Journal, CODEN (USA); CRJHAS, 3(3): 46-56,

8. Echegi Christian Uche (2019), Effects of Activating Agents on the Characteristics of Activated Carbon Produced from Sub-bituminous Coal, International Journal of Research in Engineering and Applied Sciences, Vol. 9, Issue 1, 14-29.

9. Ejikeme E.M., Ejikeme P.C.N. and Echegi U.S.C. (2015), Effect of Microwave Activation on the Removal Efficiency of Hambugar Seed Shell, JMEST, Vol. 2, Issue II: 2940-2946.

10. Foo K. Y and Hameed B.N (2012) Preparation, Characterization and Evaluation of Adsorption Properties of Orange Peel Based Activated Carbon via Microwave-Induced $\mathrm{K}_{2} \mathrm{CO}_{3}$ Activation, Bioresoure, Technol. 104: 679 - 686.

11. Foo Keng Yuen and Hameed B.H (2009), Recent Developments in the Preparation and Regeneration of Activated Carbons by Microwaves, Advances in colloid and Interface Science, 149:19-27.

12. Hesas Hoseinadeh R., Arami-Niya A., David Wan W. M.A and Sahu J. N., (2013), Comparison of Oil Palm Shell Based Activated Carbons Produced by Microwave and Conventional Heating Methods using $\mathrm{ZnCl}_{2}$ Activation. Journal of Analytical and Applied Pyrolysis, 104: 176-184.

13. Li W., Peng J., Zhang L., Yang K. Xia H; Zhang S., and Guo S.H (2009) Preparation of Activated Carbon from Coconut shell Chars in Pilot-Scale Microwave Heating Equipment at 60W, Waste Management, 29 (2):756-760.

14. Lillo-Rodena M.A., Juan J., Carzola-Amorous D., Linares-Solon A. (2004), About Reactions Occurring during Chemical Activation with Hydroxides, Carbon 42: 13711375 .

15. Liu Q.S., Zheng T., Wang P., and Guo L. (2010), Preparation and Characterization of Activated Carbon from Bambo by Microwave-Induced $\mathrm{H}_{3} \mathrm{PO}_{4}$ Activation, Industrial Crops and Products, 31(2): 233-238.

16. Mao H., Zhou D., Hashisho Z., Wang S., Chen. H. and Wang H. (2015), Preparation of Pinewood and Wheat Straw-based Activated Carbon via a Microwave-assisted KOH Treatment and Analysis of the Effects of Microwave Activation Conditions, Bioresources 10(1): 809-821.

17. Rafsanjani H.H, Kamandari H; Najjarzadeh H. (2013), Study on Pore and Surface Development of Activated Carbon Produced from Iranian Coal in a Rotary Kiln Reactor, Iranian Journal of Chemical Engineering, Vol.10, No.3; $27-33$.

18. Zawani N.M., Hamzah Faszlena, Sarif M., Manaf F.A. and Idris A. (2017) Characterization of Activated Carbon using Chemical Activation, Microwave Ultrasonic System, Malaysian Journal of Analytical Sciences, Vol. 21, No. 1, 159 - 165. 